\title{
A Juventude En-Cena na Escola: a educação no encontro com a cidade
}

\author{
Lorenna Pinheiro Rocha' \\ Maria Celina Peixoto Lima' \\ 'Universidade de Fortaleza (UNIFOR), Fortaleza/CE - Brasil
}

RESUMO - A Juventude En-Cena na Escola: a educação no encontro com a cidade. A tradicional aliança entre educação e trabalho vem-se configurando numa aparente adesão das práticas educativas às engrenagens do capitalismo. Partindo da análise dos efeitos da entrada dessa configuração discursiva no espaço escolar, problematiza-se a hipótese da transição de um modelo educativo fundamentado numa formação cultural, tal como discutida por Adorno, em direção ao que entendemos como formação profissional. Segue-se a apresentação de uma pesquisa-intervenção no contexto de uma oficina de fotografias, cujos resultados apontam para o potencial da arte em subverter a lógica do ensino tecnicista, criando outro cenário de encontro da experiência educativa com a cidade, para além do norteado pela inserção no mercado do trabalho.

Palavras-chave: Educação. Psicanálise. Formação Cultural. Formação Profissional. Oficina de Fotografia.

ABSTRACT - Youth In-Scene at School: education in the encounter with the city. The traditional alliance between education and laborhas been taking shape in the apparent adherence of educational practices to the machinations of capitalism. Starting from the analysis of the effects of the entry of this discursive configuration into schools, our hypothesis is that we are watching the transition from a cultural qualification, as discussed by Adorno, to a professional qualification. In this article, we intend to present the results of a research through intervention we accomplished in the context of a photography workshop, and which point to the potential of art to subvert the logic of a technical education, creating another scenario for the encounter between education and the city, beyond one that is guided by inserting the young into the labor market.

Keywords: Education. Psychoanalysis. Cultural Formation. Professional Formation. Photography Workshop.

Educação \& Realidade, Porto Alegre, v. 46, n. 1, e109163, 2021. 
A Juventude En-Cena na Escola

\section{Introdução}

Em que consiste, afinal de contas, a educação de um jovem? A relevância da pergunta pode vir a ser questionada pela banalidade que lhe caracteriza, mas é exatamente ao tentarmos respondê-la que nos deparamos com a imprecisão do que seria educar um jovem nos tempos atuais, sobretudo se levarmos em conta a crescente migração dos valores econômicos para o campo educacional presenciada nas últimas décadas. Assim, vemo-nos convocadas a ultrapassar a obviedade a que, à primeira vista, a pergunta pode parecer referida e adentrar a problemática de modo mais contundente.

Devido à complexidade que, paradoxalmente, lhe atribuímos, propomos, aqui, um recorte transversal por distintos campos que retomam tal problemática num ponto que servirá como contextualização para a nossa discussão - e que, direta ou indiretamente, vem sendo abordado e analisado por diversos autores (Adorno; Becker, 2003a; Adorno; Becker, 2003b; Laval, 2019; Saviani, 1994; 2003; Costa, 2009): a associação entre o lugar conferido à educação de jovens numa sociedade nomeadamente capitalista e a preparação desse público para a entrada no mercado de trabalho.

A esse respeito, se retomarmos a Lei de Diretrizes e Bases da Educação Nacional (Brasil, 1996), mesmo no que concerne às suas mais recentes atualizações, percebemos como é clara a diferença discursiva no tratamento dado ao ensino médio quando o comparamos aos demais segmentos da educação básica. Ao passo em que as propostas direcionadas à educação infantil foram tomando contornos de uma via de inserção das crianças no plano da cultura, vinculando-se a práticas sociais e culturais num contexto mais amplo, a tônica da educação de jovens parece recair sobre uma formação tecnicista voltada, basicamente, para a inserção profissional.

Tal constatação torna-se ainda mais evidente ao analisarmos os principais documentos que norteiam a construção dos currículos escolares voltados ao público jovem - Diretrizes Curriculares Nacionais da Educação Básica (Brasil, 2013); Diretrizes Curriculares Nacionais para a Educação Profissional Técnica de Nivel Médio (Brasil, 2012); Referenciais Curriculares para a Educação Profissional Técnica (Brasil, 2000). Neles, as noções de habilidade e de competência vêm ganhando lugar de destaque como orientadores na construção de propostas pedagógicas que “[...] gerem desempenhos eficientes e eficazes" (Brasil, 2000, p. 10) - terminologias, como sabemos, bastante caras ao mundo empresarial. Dos alunos, portanto, é esperado que finalizem seus percursos escolares com certos conjuntos de habilidades e competências bem desenvolvidos, de modo a aumentarem o seu potencial de empregabilidade.

Em contrapartida, ao adentrarmos o contexto escolar propriamente dito, assistimos à denúncia comumente feita pelos jovens sobre a falta de um sentido intrínseco nos conteúdos que lhes tentam ensinar: professor, por que estamos estudando isto? Para que serve afinal de contas? As respostas a essas perguntas, não raro, se valem de frágeis argumentos 
que não conseguem mais do que defender o valor de certos conhecimentos a partir do que podem proporcionar em termos de conquistas futuras: para passar no ENEM!. Assim, questionamo-nos: estaria a educação escolar transformando-se num investimento, no sentido econômico do termo, deixando de configurar um fim em si mesma para funcionar como meio para se alcançar sucesso profissional e retorno financeiro? Nesse cenário, que valor ainda poderíamos atribuir ao conhecimento, ao saber e à cultura?

O fato é que, se um dia a escola centrou seus esforços na oferta de uma formação intelectual e cidadã pela transmissão dos valores da cultura e dos referenciais simbólicos da sociedade (Laval, 2019) numa tentativa de promover, pela via do saber, o esclarecimento e a autonomia necessários à emancipação ${ }^{1}$, esse propósito vem sofrendo profundas transformações com o advento do capitalismo.

Com base nessa problematização inicial, neste artigo, nos propomos, num primeiro momento, a contextualizar historicamente as relações que se estabelecem entre a educação de jovens e a sua preparação para o mercado de trabalho, delimitando a transição de um modelo de formação fundamentada numa experiência formativa em direção ao que entendemos como formação profissional. Em seguida, discutiremos os resultados de uma pesquisa-intervenção que desenvolvemos no contexto de uma oficina de fotografias ofertada a alunos de uma escola estadual de educação profissional, em que tentamos subverter a lógica do ensino tecnicista através da arte, construindo, a partir da singularidade do gesto fotográfico, outras possibilidades de encontro com a experiência educativa.

\section{Educação: ainda uma experiência formativa?}

Embora a aliança entre as práticas educativas voltadas à juventude e a inserção desse público na pólis pela via do trabalho tenha ganho mais notoriedade na contemporaneidade, ela, certamente, não configura um fenômeno recente. Saviani (1994) nos adverte que, já nas comunidades primitivas, em que prevalecia o modo de produção comunal, “[...] a educação coincidia inteiramente com o próprio processo de trabalho" (p. 2), sendo esse último entendido como a ação do homem sobre a natureza, com o intuito de adaptá-la às suas necessidades. Nesse contexto, a educação consistia, basicamente, na transmissão para as novas gerações das técnicas de produção que garantiriam a manutenção da existência humana; assim, os homens educavam-se e educavam os mais jovens pelo trabalho, e estes aprendiam a trabalhar trabalhando, já que a atividade laboral consistia no meio de produção de suas próprias existências.

Tomemos como exemplo os artesãos: a arte do ofício era transmitida do mestre ao aprendiz a partir de um saber-fazer construído pelo próprio sujeito, e era justamente esse ofício que lhe garantia um certo lugar na comunidade (Huberman, 1981). Tal modalidade de transmissão implicava diretamente na construção não apenas de um conheci- 
mento a ser passado de uma geração a outra, mas de um saber cuja validade só poderia ser estabelecida pela via da experiência, o que, segundo Saviani (2003), configuraria um verdadeiro processo de aprendizagem.

No entanto, no momento em que o modelo de produção comunal perde espaço pela divisão da sociedade em classes, colocando, de um lado, os proprietários de terra - que não precisavam trabalhar diretamente com ela para assegurar a sua existência - e, do outro, os serventes - responsáveis por garantir, não só o seu sustento, mas o dos seus senhores (Ribeiro, 1993) -, o cenário se modifica sobremaneira.

A origem da escola se situa precisamente nesse contexto; voltada à classe dominante, a educação escolar contrapunha-se à educação geral, que acontecia no próprio processo de trabalho e era dirigida à maioria da população. Cabia, então, à escola ocupar-se das atividades consideradas nobres e intelectuais, tais como a transmissão, para as novas gerações, dos valores culturais, da arte da palavra, dos conhecimentos acerca dos fenômenos naturais e das regras de convivência social (Saviani, 1994).

Quando o modo de produção capitalista ganha força, em especial a partir da Revolução Industrial, é que vemos aparecerem os primeiros indícios da associação entre educação escolar e trabalho ou, para sermos mais exatas, entre educação escolar e mercado de trabalho. Se, antes, o artesão era senhor da sua produção, ao tornar-se funcionário fabril, seu fazer é desmembrado em diversos fragmentos de pequenos processos sobre os quais ele não mais detém controle. Perde-se, portanto, o domínio sobre o produto, mas também sobre o próprio processo de produção. A máquina se torna a materialização das funções intelectuais no processo produtivo, da qual, inevitavelmente, o trabalhador encontra-se alienado (Saviani, 2003). Com isso, o saber-fazer perde espaço, e o automatismo do puro fazer, atravessado pelo imperativo da reprodutibilidade da técnica, entra em cena. Se, antes, o trabalho consistia no processo por meio do qual o homem, para garantir a sua existência, adaptava a natureza às suas necessidades, agora, o homem é que precisa adaptar-se ao trabalho para garantir a sua sobrevivência.

A preparação das novas gerações para adequarem-se e aderirem à nova lógica produtiva torna-se urgente. A capacitação e a formação educacional e profissional dos jovens passam a configurar elementos estratégicos a serem investidos, como forma de garantir não apenas o aumento da produtividade, mas da própria capacidade produtiva dos indivíduos (Costa, 2009) e, portanto, da lucratividade que eles representariam ao mercado. A educação passa, então, a ser entendida como decisiva para o desenvolvimento econômico de uma nação, de modo que a escola, por configurar um espaço de educação formal por excelência, é também convocada a responder a interesses de cunho econômico. Educa-se numa perspectiva de instrumentalização do indivíduo, de modo a agregar valor ao capital humano (Schultz, 1973) que ele tem a oferecer ao mercado, ficando a escola submetida aos imperativos do sucesso profissional e da eficiência - costumeiramente traduzidos pelo signo do 
acúmulo de capital, já que ser bem-sucedido implica diretamente em ganhar muito dinheiro.

A problemática que reconhecemos aí, no entanto, não diz respeito, puramente, ao fato de as escolas também se encarregarem da tarefa de oferecer a seus jovens alunos algum espaço de preparação para o trabalho, principalmente se levarmos em conta os preocupantes índices de desemprego que marcam a realidade brasileira.

Nossa questão, na verdade, vai na direção de problematizar o quanto a educação de jovens, ao eleger como seu principal objetivo a inserção profissional de seus alunos e a sua adaptação à lógica dominante, vem sendo pensada e organizada numa relação quase que de servidão com o capitalismo. Nesse contexto, como enfatizam Bandeira e Oliveira (2012), os currículos escolares, tentando responder a demandas de clara inspiração mercadológica, acabam organizados de modo fragmentado, e os conteúdos programáticos são desarticulados de tal maneira que não há uma estrutura transversal que desperte a curiosidade intelectual, o interesse dos alunos pelo conhecimento, ou a sua criticidade diante dos problemas que nos acometem enquanto sociedade. Assim, as escolas acabam por focar em estratégias individualistas, que parecem excluir a dimensão subjetiva dos processos educativos e a própria perspectiva coletivizante do conhecimento - já que a competitividade característica do mundo corporativo invade o território escolar, transformando colegas em concorrentes na corrida para se conquistar o primeiro lugar da turma, uma vaga nas universidades ou, mais adiante, no mercado de trabalho.

A esse respeito, Saviani (2003) nos adverte sobre os riscos de que o ensino médio, focando em fazer chegar aos alunos os conhecimentos práticos necessários para a sua adaptação às demandas de mercado, acabe por reduzir-se a uma tecnização da juventude pelo seu adestramento em técnicas produtivas. Nesse contexto, as demandas sociais dirigidas aos jovens, sendo veiculadas em termos de um êxito escolar como condição única para o sucesso profissional, pois é preciso estudar para ser alguém na vida, podem levar, ou à reativação da questão do desejo dos pais, do qual o jovem precisa desvencilhar-se (Freud, 2006a), ou ao abismo do ser ninguém, que deflagra a realidade de uma Juventude Desamparada (Aichhorn, 2006) sem referências nas quais possa sustentar-se em sua transição para o mundo adulto.

Submetidos ao tecnicismo que surge como traço diferencial da educação contemporânea, alguns jovens, desconfiando de que, tal como a promessa edípica, um diploma poderá não garantir a satisfação almejada, ao concluírem que não serve pra nada aprender, tomarão o caminho de satisfações mais imediatas pela adesão a objetos de consumo, outros entrarão num recolhimento quase autístico no campo do virtual, na internet e nos jogos eletrônicos (Lima; Lima, 2011).

Violência, indisciplina, desinteresse, baixo rendimento e altos índices de evasão escolar - que quintuplicam no ensino médio (11,7\%) quando comparados aos anos iniciais do ensino fundamental $(2,3 \%)$ 
(Brasil, 2017) - surgem como exemplos que vêm ilustrar este preocupante cenário. Em situações ainda mais graves, temos a adesão de um número cada vez maior de jovens a práticas autolesivas, à depressão, ao consumo abusivo de álcool e outras drogas e às tentativas de suicídio.

Esse quadro evidencia a gravidade da crise que o campo educacional enfrenta na atualidade, deixando incertos os contornos de sua atual função social, daí a complexidade a que fizemos referência logo no início deste artigo. No debate intitulado Educação - para quê?, Adorno e Becker (2003b), envolvidos com essa questão, travam um diálogo que traz importantes operadores para pensarmos os impasses envolvidos na definição de um objetivo específico ou de uma finalidade última da educação na atualidade. A esse respeito, Adorno afirma que

\begin{abstract}
[...] ocorre algo semelhante com a educação e a formação. Houve tempos em que esses conceitos, como dizia Hegel, eram substanciais, compreensíveis por si mesmos a partir da totalidade de uma cultura, e não eram problemáticos em si mesmos. Mas hoje tornaram-se problemáticos nestes termos. No instante em que indagamos: 'Educação para quê?', onde este 'para quê' não é mais compreensível por si mesmo, ingenuamente presente, tudo se torna inseguro e requer reflexões complicadas. E sobretudo uma vez perdido este 'para quê', ele não pode ser simplesmente restituído por um ato de vontade, erigindo um objetivo educacional a partir do seu exterior (Adorno; Becker, 2003b, p. 139).
\end{abstract}

A problemática apontada por Adorno constitui, aqui, um importante ponto de partida: ao se erigir objetivos para a educação a partir do seu exterior, inevitavelmente, perde-se a clareza da finalidade que lhe seria intrínseca. A progressiva entrada dos valores econômicos no campo educacional, funcionando como norteadores que conduzem as práticas educativas em direção a uma formação profissional, parece vir deturpando a própria compreensão da educação enquanto uma experiência formativa.

A noção de formação, aqui, é preciso esclarecer, não consiste, meramente, num sinônimo de educação ou de desenvolvimento. Por ela, devemos entender o processo pelo qual "[...] a cultura [é $]^{2}$ tomada pelo lado de sua apropriação subjetiva” (Adorno, 2010, p. 9). Fazendo referência à noção alemã de Bildung, costumeiramente traduzida como formação cultural, a experiência formativa implicaria em abrir espaço a que os indivíduos, pela luz da razão, ascendam ao esclarecimento, conquistando, com isso, a sua autonomia (Kant, 1985 [1874]). Assim, ela consistiria na via régia de promoção da emancipação, por meio da qual as pessoas poderiam, com liberdade, escolher seus próprios caminhos, sustentar suas próprias convicções e responsabilizar-se por elas, com o intuito de, coletivamente, construir uma sociedade mais justa para todos.

Seguimos, hoje, quase que na contramão dessa direção. A ciência, que um dia já sustentou as descobertas revolucionárias que fizeram 
avançar o mundo, vem perdendo seus atrativos enquanto saber emancipatório (Voltolini, 2012). Convertidos em força produtiva que fazem girar as engrenagens da maquinaria capitalista, os conhecimentos produzidos e acumulados pela humanidade ao longo da história não mais viabilizam uma estrutura educacional erigida sobre os princípios do esclarecimento e da autonomia, afinal, não se educa para a emancipação, mas para o seu direto oposto: a adaptação às demandas de mercado - não é à toa que assistimos a uma progressiva substituição das antigas feiras de ciências pelas inovadoras feiras das profissões.

Fica claro, portanto, que a educação vem, progressivamente, se distanciando de uma perspectiva formativa. Se a escola atual forma para o trabalho, não podemos deixar de levar em conta que esse trabalho se define pela racionalização progressiva dos processos de produção industrial, eliminando os resquícios da antiga atividade artesanal e, com ela, a própria dimensão da aprendizagem resultante da experiência no ofício (Adorno, 2003). Assim, diferentemente do modelo de formação observado no antigo trabalho artesanal, que se fundamentava na construção de um saber-fazer a ser transmitido entre gerações como meio de manutenção da própria existência humana, a formação profissional endereçada à juventude contemporânea funciona como instrumento do capital e, nesse contexto, o trabalho acaba por assumir uma configuração alienada e alienante.

Em nome de uma racionalidade produtivista, o próprio sentido ético dos processos formativos e educacionais encontra-se à deriva nas revoltas marés econômicas, sem pontos de ancoragem onde possam amparar-se. Assim, o sistema educacional que hoje forma os indivíduos consegue, tão somente, chegar ao que Adorno (2010) veio a nomear como semiformação (Halbbildung). Estando as relações sociais de um modo geral regidas pela lógica mercantilista, as práticas educativas passam a conduzir, tanto no aspecto cognitivo como no afetivo, a uma submissão passiva à falsa ideia de felicidade obtida através dos bens de consumo (Bandeira; Oliveira, 2012). A semiformação, portanto, “[...] é o espírito conquistado pelo caráter de fetiche da mercadoria” (Adorno, 2010, p. 25), que fragiliza as condições subjetivas necessárias à efetivação do caráter emancipatório da formação (Bandeira; Oliveira, 2012).

Nesse contexto, uma nova estrutura cultural toma forma. Nela, tudo se torna objeto de consumo, não mais possuindo valor de uso, mas passando a ter valor de troca. A esse respeito, Voltolini (2012), amparado na fórmula do discurso do capitalista proposto por Lacan, chama a atenção para o modo particular pelo qual o sujeito, regido por uma lógica mercantilista, passa a se relacionar com o objeto.

O objeto, agora coisificado por sua produção em série, empirizado pelo discurso científico, desconectado de seu fundo de ausência, tal como destacou a psicanálise com os conceitos de pulsão e de desejo, vem determinar, artificialmente, um 'sujeito em série', voltado para o consumo. A hiperinflação do objeto, empreendida pelo capitalismo, visa estabelecer entre o sujeito e o objeto uma comple- 
mentaridade sem arestas, o objeto sob medida na linguagem mercadológica, a existência da relação sexual, nos termos lacanianos, o paraíso nos termos bíblicos (p. 111)

Esses objetos, dentre os quais podemos situar o próprio conhecimento científico, circulam no mercado, sustentando a ideia de que "[...] nossa felicidade depende apenas de nossa competência pessoal" (Bauman, 2001, p. 87). Mas o que restaria de atrativo na busca pelo saber emancipatório, se o paraíso dos objetos é ofertado sem limites?

Diante deste cenário, questionamo-nos: seria possível operar uma torção que subverta a lógica de ensino pautada no tecnicismo em direção a uma proposta educativa fundamentada numa perspectiva formativa que reconduza o jovem, pela luz da razão, em direção ao esclarecimento, à autonomia e, portanto, à emancipação, promovendo a sua inserção não apenas no mercado de trabalho, mas na cultura, no laço social e, portanto, na pólis?

\section{Da Imagem (Fotográfica) ao Movimento (da Cidade)}

Foi com base nessa aposta que realizamos uma pesquisa-intervenção orientada pela psicanálise, a partir da construção de um dispositivo grupal no formato de uma oficina de fotografias, ofertada aos alunos do ensino médio de uma escola estadual de educação profissional. A ideia consistia em oportunizar, dentro da escola, uma prática educativa diferente das modalidades tradicionais de ensino, onde a subjetividade pudesse comparecer como motora do processo educativo. Objetivávamos, com isso, deslocar o epicentro da nossa proposta desde uma perspectiva adaptativa à lógica de mercado, em direção a um posicionamento mais crítico da realidade, em que pudéssemos, pela implicação do sujeito, encenar uma prática inspirada nos princípios da emancipação.

\section{Sobre a Metodologia em Cena}

Advertidas dos efeitos de uma educação pautada no tecnicismo, que, como vimos, parece excluir a dimensão subjetiva dos processos de ensino-aprendizagem, em nosso delineamento metodológico, priorizamos lançar mão de um método onde os alunos pudessem comparecer como sujeitos, mas a partir da concepção de sujeito que deriva da subversão que a psicanálise opera em relação ao campo científico (Elia, 1999). A explicação de tal subversão podemos encontrar em Lacan (1998), quando afirma que a psicanálise retira o sujeito da condição de exclusão na qual a ciência o colocou, (re)incluindo-o no campo de sua própria experiência. Essa inclusão, no entanto, só se faz possível pela via do inconsciente, de modo que o sujeito da psicanálise só pode ser incluído como sujeito do inconsciente e, portanto, como sujeito do desejo.

Foi, então, desde o lugar de sujeitos do desejo que os jovens foram convidados a participar da pesquisa que, como já dito, possuía um ca- 
ráter interventivo. Esse método, conforme nos esclarece Pereira (2013), encontra-se atrelado a processos de subjetivação e de desnaturalização de si e do outro com quem se pesquisa, de modo a convocar o sujeito a entrar em cena, produzindo o que não se espera: uma novidade, um novo significante ou mesmo uma imagem fotográfica singular, algo que o surpreenda e o subjetive. Essa foi a dimensão da intervenção que se corporificou em nosso estudo: intervir, no seio de um pesquisar, apostando que, daí, algum efeito subjetivo se fizesse produzir.

Embora não estivéssemos inseridas num dispositivo propriamente analítico, inspiramo-nos nos princípios éticos que norteiam a sua clínica. Assim, buscamos adotar uma atitude livre de pressuposições teórico-conceituais, possibilitando aos jovens um espaço propício à expressão do inconsciente e à formulação de um saber singular, processos que, em nossa proposta, se deram pela mediação das fotografias produzidas.

A escolha por esse recurso mediador se deu, em parte, pelo caráter sedutor da imagem na cultura contemporânea, sobretudo, entre os jovens, e, por outro lado, pela discussão que Benjamin (1994) trava sobre a câmera cinematográfica, abrindo margem a sua articulação com a própria dimensão da técnica em psicanálise. Rouanet (2008) explicita que o olhar do analista e o olhar da câmera, em seus distintos fazeres, se encontram completamente fixados num objeto, seja o que se fotografa, seja o inconsciente. Assim, a teoria dos lapsos de linguagem de Freud cumpriria um papel homólogo ao da câmara na medida em que ambos paralisam um fluxo, seja da linguagem, seja do movimento, revelando um fragmento perdido - um ato falho, um termo deslocado de sentido ou um detalhe da realidade factual - não acessível ao estado de consciência em suas condições normais.

A fotografia, portanto, cumpre o papel de capturar fragmentos que passariam despercebidos, não fosse o olhar sensível de quem os fotografa. Tais fragmentos, imortalizados pelo gesto fotográfico do seu autor, abrem a possibilidade de uma conversão do fluxo do movimento da realidade em direção ao fluxo narrativo do sujeito-fotógrafo, enlaçando a imagem produzida num plano discursivo que o recoloca diante de si mesmo - já que, como nos alerta Winnicott (1975), ao se falar de um objeto criado-encontrado, é sobre si mesmo que se fala. Assim, em nossa pesquisa, mais do que o produto fotográfico em si, era o gesto fotográfico, entendido como o instante em que a subjetividade do fotógrafo, através do seu olhar, funciona como mediadora entre o sujeito e a sua produção, que nos interessava.

É preciso esclarecer, ainda, que a proposta caminhava em direção a sustentar um posicionamento crítico frente à lógica imediatista e mercadológica da cultura da imagem (Miranda, 2007), tendo em vista que, em geral, ela exclui a dimensão subjetiva da criação ao negar qualquer possibilidade de mediação entre o sujeito e aquilo que ele posta, curte e compartilha. A recomendação inicial, portanto, era que os jovens pudessem distanciar-se do óbvio, das selfies, buscando apreender aqui- 
A Juventude En-Cena na Escola

lo que representasse seus percursos e travessias desde o espaço escolar até a oferta de laço social que se origina na cidade.

Tratava-se, assim, de um fotografar que faz referência à emblemática figura do flâneur (Benjamin, 1989). Este personagem, nascido em meio às paisagens urbanas do século XIX, vagueia pela cidade de Paris junto à multidão, recolhendo os detalhes do caminho percorrido num passeio por tempos corroídos pela história. Como o narrador sucateiro (Gagnebin, 2006), não recolhe grandes feitos, mas aquilo que é deixado de lado como algo sem significação, o que parece não ter sentido nem importância, escapando, assim, da história oficial, mas podendo ser retomado no presente para compor novos futuros.

Foi com base nessas referências que intitulamos a oficina como Da imagem ao movimento: restos de um Futuro ${ }^{3}$, chamando a atenção para um possível deslocamento a ser empreendido pelos jovens desde a imagem fotográfica por eles produzida em direção ao movimento subjetivante da cidade; deslocamento esse em que os restos aparentemente insignificantes capturados em seus percursos poderiam ser retomados num plano discursivo. Com isso, portanto, objetivávamos que eles pudessem criar suas próprias estratégias de inserção na pólis, para além daquela delimitada pela via do trabalho. Assim, o registro daquilo que lhes saltasse aos olhos em meio às travessias empreendidas e a abertura de um espaço destinado à construção de narrativas singulares a partir de tais registros surgiriam como tentativa de promover vias de afirmação criadora para esses sujeitos-alunos, abrindo-lhes novas possibilidades de experienciar a juventude, sem as costumeiras exigências por eficiência, desempenho e rendimento que demarcam a transição para o mundo adulto.

Seguindo essa perspectiva de trabalho, apresentamos a proposta aos alunos da escola onde a pesquisa foi realizada e, dentre aqueles que demonstraram interesse e disponibilidade para participar, sorteamos 12 jovens para montarmos o grupo. Ao todo, tivemos 12 encontros, que aconteceram quinzenalmente e contaram com a participação da doutoranda também autora deste artigo e de três alunos de iniciação científica, sendo dois provenientes do curso de Psicologia e um do curso de Publicidade e Propaganda.

A autorização para a participação na pesquisa foi concedida por meio de Termo de Consentimento Livre e Esclarecido (TCLE), assinado pelos responsáveis legais pelos jovens, e de Termo de Assentimento (TA), assinados pelos próprios participantes. Adotamos como critério de inclusão/exclusão: ter idade variando entre 14 e 18 anos, estar regularmente matriculado na escola em questão no ano de 2019, além de desejar, voluntariamente, participar da pesquisa.

No que diz respeito às atividades desenvolvidas, inicialmente, incluímos momentos preparatórios, onde, numa vertente mais teórica, trabalhamos a história da fotografia e o seu caráter potencialmente subversivo, e, num componente mais prático, contando com a participação de um professor-fotógrafo com vasta experiência com o público jovem, 
tivemos orientações mais técnicas sobre a fotografia com telefones celulares - dispositivo escolhido para ser utilizado na oficina, em função da facilidade de acesso, já que todos possuíam seus próprios aparelhos.

Ainda antes de iniciarmos o momento do ato fotográfico em si, organizamos uma visita guiada ao Museu da Fotografia de Fortaleza como sensibilização inicial para outras modalidades possíveis do fotografar, não necessariamente atreladas ao que costuma ser veiculado nas redes sociais e nas campanhas publicitárias de um modo geral.

Após essa visita, criamos um instagram 4 , que funcionou como espaço de compartilhamento das imagens produzidas, mas também como fonte de inspiração, já que o perfil criado seguia perfis de fotógrafos de diferentes lugares do mundo.

Como os encontros aconteciam quinzenalmente, os participantes, foram orientados a, ao longo de duas semanas, fotografar instantes do seu cotidiano que, por algum motivo, lhes chamassem a atenção. Posteriormente, eram convidados a falar sobre suas produções. Assim, era aberto um espaço onde a palavra podia circular, construindo uma espécie de narrativa-testemunho dessa experiência compartilhada por e entre vários.

Ao final, organizamos uma exposição na escola com as fotografias selecionadas pelos próprios jovens, onde puderam apresentar o resultado desse trabalho para a comunidade escolar, tornando público os restos capturados em seus percursos dentro e fora da escola.

O material trabalhado na pesquisa foi proveniente de duas fontes principais: 1) transcrições dos encontros e 2) registros fotográficos produzidos. Para a análise das transcrições, inspiramo-nos no método que Coutinho e Poli (2019), fazendo referência ao modo particular de escuta a ser adotado pelo analista no contexto clínico - a atenção flutuante (Freud, 2006b) -, define como leitura flutuante. Realizamos, então, uma leitura flutuante do material de campo, fossem as transcrições dos encontros, fossem as próprias fotografias criadas durante a oficina, numa tentativa constante de fazer decantar algo que, de modo inusitado e surpreendente, tal como um lapso de linguagem, pudesse comparecer como índice daquilo que a pesquisa permitiu produzir e/ou apreender.

Assim, as falas sobre as quais, aqui, lançaremos luz correspondem ao que pôde decantar desse trabalho de leitura das narrativas construídas no coletivo, funcionando como inspiração para que pudéssemos pensarmos a partir delas. Durante esse processo, algumas questões foram tomando corpo e forma. Como, desde Lacan (1988), aprendemos que, em psicanálise, não procuramos, mas achamos - e "[...] isto quer dizer que, no campo de Freud, basta a gente se abaixar para colher o que há para achar” (Lacan, 1988, p. 211) -, passemos, agora, à discussão sobre alguns dos nossos achados. 
A Juventude En-Cena na Escola

\section{‘Achados' Recolhidos no Percurso}

Se a educação contemporânea, assumindo o papel de oferecer uma formação profissional adequada às demandas econômicas que lhe são endereçadas, imprime, em suas práticas, a marca indelével da lógica de mercado, não é surpresa que toda a comunidade escolar acabe enlaçada numa trama que convoca seus atores a encarnarem o discurso capitalista. Dessa convocação, os alunos não estão isentos e parecem tomados pela ideia fortemente difundida de que precisam aproveitar o tempo da escola para prepararem-se para uma vida profissional de sucesso.

Tal constatação foi evidenciada logo nos primeiros encontros da oficina de fotografias. Era nítido o modo como os jovens haviam incorporado a perspectiva instrumental dos conhecimentos transmitidos e das experiências vivenciadas no espaço escolar, deflagrando uma disseminação bastante efetiva da ideia de que o valor daquilo que se aprende está embutido no que ele pode proporcionar em termos de aumento do potencial de empregabilidade para o aprendente; ou seja, se agrega valor ao capital humano que o sujeito terá a oferecer ao mercado, vale à pena ser aprendido/vivenciado.

Eu me inscrevi para essa oportunidade para poder colocar no meu currículo, porque eu quero seguir nessa carreira da comunicação. Então eu fiquei bem animado ${ }^{5}$.

Eu me interessei pelo curso, porque surgiu uma oportunidade para trabalhar como recepcionista em eventos, e aí eles olham muito os intagra$m s$ das meninas. Então eu queria aprender [sobre fotografia] para deixar o meu feed ${ }^{6}$ mais organizado, mais bonito, sabe?

O significante oportunidade era uma constante em nossas conversas. Estudantes da rede pública num país em que a promoção de uma educação pública de qualidade, claramente, não é uma prioridade dos governantes, viam como mais restritas as suas chances de dar certo na vida. Assim, toda nova proposta ofertada na escola parecia passível de ser interpretada como uma nova oportunidade de ampliarem as suas possibilidades de entrada/sustentação no mercado de trabalho, onde a concorrência, como sabemos, é, de fato, desleal. E isso, por si só, não seria algo problemático, afinal, o que vier a promover o engajamento e a implicação dos jovens nas atividades propostas na escola - possibilitando, quem sabe, a redução dos altos índices de evasão que observamos no ensino médio -, tem sua validade assegurada. A questão é que tal concepção vem testemunhar a alienação à lógica de mercado a que nossos jovens são conduzidos, já que, também para eles, as práticas educativas acabam condicionadas a critérios profissionalizantes em detrimento daquilo que poderiam oferecer em termos de uma experiência formativa.

Na oficina de fotografias, ao serem questionados sobre qual entendiam ser a função da escola, não foi surpresa que a dimensão da formação profissional se mostrou unânime. Nessa direção, as falas dos 
alunos pareciam se pautar em enunciados já prontos, internalizados, talvez, a partir daquilo que se dissemina no tecido social.

A educação é basicamente uma das coisas que faz um país. O que faz um país andar para frente é a educação, porque é por ela que a gente se forma. Todo profissional teve que estudar na escola um dia para chegar aonde chegou, né? A educação é o futuro da nação.

É aquela coisa né? A gente tem que estudar se quiser ser alguém na vida. A escola serve mais para a gente garantir um futuro em relação a emprego, faculdade, essas coisas. Acho que é para isso que ela serve.

Com o desenrolar dos encontros, no entanto, percebemos uma certa torção se fazer operar. O significante curso, por exemplo, começou a sair de cena, à medida que os jovens foram compreendendo que a oficina de fotografias não funcionaria como uma sala de aula e nem tinha os mesmos propósitos de uma. O próprio espaço físico em que nos encontrávamos servia como um demarcador da diferença necessária. Por vezes, nosso lócus de trabalho era a biblioteca; em outros momentos, o pátio da escola; noutros ainda, o laboratório de informática. Em todos eles, porém, um traço comum: as cadeiras em roda, para que pudéssemos olhar uns aos outros e a palavra tivesse livre caminho para circular, demarcando, assim, a desierarquização dos lugares que caberiam a cada um - pesquisadores e participantes da pesquisa. Nesse sentido, assumindo uma outra postura e sendo convocados a falar a partir de um outro lugar, a própria concepção acerca da função que caberia à escola pôde ser problematizada e ressignificada no coletivo. Ao concluírem que a escola deveria oferecer uma formação voltada para a cidadania, se aproximavam da concepção de educação que, segundo Laval (2019), um dia, a escola já sustentou.

Eu acho que a escola fica muito focada nessa parte [profissionalizante], mas devia ir além disso; a nossa formação como pessoa tem que ir além disso, do que se vê na escola.

A escola deveria educar para a vida, para a cidadania.

Muitas pessoas acham que a escola deve ensinar o que é ser um bom cidadão. Mas, o que é esse cidadão? É um cara que terminou o ensino médio todo, se formou na faculdade de medicina, tem doutorado, uma esposa magra, dois filhos, um cachorro e uma casa. Mas cidadão, ao pé da letra, é aquele que nasceu na cidade, né? Não tem a ver com isso. O que eu quero dizer é que a gente não precisa, exatamente, ter tudo isso para ser educado. As pessoas que não seguem ou não querem isso não são educadas? Elas não têm a consciência que deviam ter? Não têm a capacidade de conviver com erros e de melhorar?

Percebemos, aí, uma modificação, tão sutil quanto determinante, na posição discursiva assumida pelos jovens. Sabemos que a teoria dos discursos proposta por Lacan (1992) designa modalidades particulares da estrutura constitutiva dos laços sociais, modalidades essas que se fundam na e pela linguagem. Os discursos, funcionando como agenciadores das relações sociais, estabelecem posições para o sujeito no que concerne ao impossível dos laços, viabilizando, assim, a análise da coletividade e a relação entre os sujeitos como efeitos de sua inscrição no simbólico (Coutinho; Poli, 2019). 
Tomando a teoria dos discursos como operadora para a nossa leitura, num primeiro momento, partindo das falas evocadas, temos uma posição discursiva dos jovens sustentada pelo discurso universitário, em que o saber é genérico, universal. Propagado na ausência de alguém que o enuncie, o saber configura-se, aí, como um enunciado sem enunciação, relegando o sujeito ao lugar de reprodutor acrítico de certas construções tomadas como verdades absolutas. A suposição de um saber do lado do sujeito que é convidado a tomar a palavra, no entanto, pôde produzir um giro discursivo em direção a uma histericização do discurso. Caracterizando-se pelo questionamento dos universalismos propagados no social, o discurso da histérica redimensiona o sujeito, conduzindo-o à posição de agente do saber.

Ao problematizarem as concepções acriticamente difundidas a respeito da educação, questionando, nesse contexto, quem seria, afinal de contas, esse cidadão bem educado que a escola deve formar, os jovens puderam fazer furo no discurso que rege a educação contemporânea. Ainda que não tenham apontado, exatamente, uma resposta tangível à questão lançada - tarefa que, como vimos, não é simples nem banal - puderam se inquietar, construir novas perguntas, desnaturalizar verdades totalizadas e, com isso, ensaiar a construção de uma outra relação possível com o espaço educativo, marcado pela singularidade da experiência de cada um no encontro com o saber e com a sua transmissão.

Adentrando, propriamente, as discussões decorrentes do compartilhamento das fotografias criadas, percebíamos tomar forma, em meio às tramas narrativas tecidas a partir dessas imagens, um posicionamento crítico frente à cultura da imagem à qual estamos todos submetidos. Inquietavam-se com o modo como as campanhas publicitárias e os influenciadores digitais pregam uma certa imagem fetichizada de felicidade, muitas vezes, incompatível com a realidade, porém apresentada como mais um bem que deve ser adquirido e consumido para que se possa ter sua condição de sujeito reconhecida (Maar, 2003). O contraditório, aí, é que, na verdade, é justamente nessa dinâmica que nos impele ao consumo irrefreado que acabamos também transformados em objetos a serem consumidos (Pereira, 2013). Nesse contexto, alguns jovens, não conseguindo construir anteparos à volúpia do Outro que, deles, goza desmedidamente, ausentavam-se dos espaços virtuais em que tais imagens propagadoras de modelos ideais tinham lugar cativo.

As pessoas acabam buscando muito a perfeição no instagram, porque é o que aparece lá. Por exemplo, alguém que faz uma viagem, posta uma foto e é isso. Então, geralmente, quando alguém vê o instagram dessa pessoa, pensa que aquilo é a vida dela. Daí isso acaba influenciando negativamente muitas pessoas. Até eu já tive problemas com isso. Comecei a ficar mal com o que eu via, aí fiquei meio desanimada e fechei o meu instagram.

Eu parei de postar foto no instagram, porque eu acho que tem dois extremos. Tem um lado muito positivo, porque é legal ver todo mundo lá, o que cada um está fazendo, mandar umas publicações aleatórias para a 
galera; mas tem um lado muito ruim, que é o julgamento. Então foi isso, eu parei de postar para não ficar preocupado.

Ainda no que concerne à temática das redes sociais virtuais, uma outra questão foi-se delineando com o passar dos encontros. Problematizavam o quanto, nelas, o uso da palavra vem sendo substituído pelo uso de imagens incessantemente compartilhadas no mundo digital, muitas vezes, consistindo em meras reproduções umas das outras, sem um traço diferencial que as caracterize e singularize. Isso se torna especialmente evidente quando traçamos um comparativo desde os antigos blogs, que funcionavam como verdadeiros diários online, até os instagrams da atualidade, que limitam a quantidade de caracteres permitidos nas legendas das postagens. O ditado uma imagem vale mais que mil palavras talvez nunca tenha feito tanto sentido como na atualidade, em que presenciamos memes e figurinhas reproduzidos na internet tornarem o recurso à palavra quase que totalmente dispensável.

Nossa proposta, seguindo na contramão dessa direção, ao funcionar como um dispositivo de escuta no coletivo, convidava os jovens a retomarem o uso da palavra na criação de uma narrativa em torno da qual as significações e sentidos pudessem circular, forçando os limites da linguagem para dar conta do real inapreensível da imagem.

Neste espaço, embora nos valêssemos de uma atividade que envolvia, sim, um componente técnico relacionado ao ato de fotografar, o fazíamos justamente numa tentativa de subverter a lógica tecnicista que caracteriza as práticas educativas contemporâneas. Lá, portanto, não buscávamos que os jovens alcançassem o enquadre perfeito, uma certa estética da imagem, ou que tomassem a oficina como um espaço potencial de preparação profissional. Apostávamos, na verdade, que os conhecimentos técnicos transmitidos pelo professor-fotógrafo na oficina ofereceriam algumas ferramentas para que, a partir da singularidade impressa no gesto fotográfico de cada um, pudessem criar algo novo, que dissesse dos percursos e travessias por eles empreendidos.

Essa experiência, encontrando sua culminância na construção de narrativas a partir das imagens criadas, puderam produzir efeitos de significação em sujeitos que, engendrados pela cultura, apontavam na direção de seu próprio desejo. Assim, amparados pelas infinitas possibilidades que se abrem a partir de uma criação autêntica e singular, alguns dos jovens acabaram por retornar às redes sociais virtuais - que configuram uma modalidade particular de laço social no contemporâneo, sobretudo para o público jovem, de modo que estar fora dele implicaria, de certa forma, em estar excluído do laço social - mas com uma nova postura e com um outro estilo de fotografia, movimento que traduz um novo modo de relação com as próprias criações.

Quando eu comecei a bater foto aqui no grupo, eu quis voltar a postar. Só que, no começo, eu ficava esperando alguém curtir e tal, mas eu parei de ficar preocupado; me libertei disso aí.

$\mathrm{Eu}$ percebi que eu gosto de bater fotos de paisagem, da natureza, dos prédios. Não sei exatamente por que, mas gosto de fazer umas invenções 
A Juventude En-Cena na Escola

diferentes das coisas que a gente vê por aí. Antes, eu não queria mostrar, mas eu vou mostrar [nas redes sociais], porque são coisas que me interessam bastante, retratar o mundo assim. E eu comecei a ver as fotos que vejo no instagram, aliás, qualquer tipo de imagem, com outros olhos.

Nesse processo, as imagens da cidade começaram a ganhar espaço. Fotografias do bairro, dos trajetos no interior dos ônibus, da praia, dos pontos turísticos e culturais da cidade, mas também daqueles que, desconhecidos, escondidos, representavam lugares de refúgio contra a velocidade do tempo citadino, passaram a ser uma constante em nossos encontros. Fotografavam, também, o não-óbvio: diante da Catedral Metropolitana de Fortaleza, por exemplo, foi o corredor que lhe abre passagem que roubou a cena.

Eu fotografei a igreja inteira numa aula de campo. É muito cultural, né? Só que quando eu vi essa paisagem do centro da cidade, ali no corredor, que, tipo assim, se eu fosse bater a foto, o retrato, ficaria o céu, as ruas, os prédios, vários fatores que eu achei muito bonito na hora e eu decidi bater essa foto. Foi esse o resultado. Fotografia nunca teve um significado tão grande assim para mim...até agora.

Na beira do mar, não eram apenas as águas e os frondosos coqueiros que chamavam a atenção, mas, numa atitude crítica da realidade, todo o lixo despejado em seus arredores, desencadeando toda uma discussão sobre a (ir)responsabilidade da sociedade com os espaços públicos da cidade.

Se vocês perceberem, aqui nessa imagem, tem uma coisa que não era para ter: o lixo. Tem uma casinha aqui atrás e tem o mar lá no fundo. $\mathrm{E}$ o mar parecia que estava limpo. Então é uma foto meio crítica, digamos assim. Porque não deveria ter o lixo que tem. E como a gente pode ver, tem pessoas que dependem da praia para viver, moram lá. Se a gente suja a praia, acaba sujando o quintal dessas pessoas, que não têm onde morar. Mas, tipo, eu estou vendo que eu tenho uma ligação muito grande com as fotografias que eu bato, eu não sei explicar, mas tem um significado muito importante para mim.

Algumas das fotografias seguiam uma linha mais representacional da realidade circundante, nas quais era mais perceptível o que o autor da imagem gostaria de retratar. No entanto, havia, também, algumas outras, de caráter mais enigmático, em que não ficava muito claro para o expectador do que se tratava ou o local em que haviam sido feitas. Essas, segundo eles, abriam mais espaço à imaginação e, poderíamos acrescentar, à construção de novas significações possíveis no encontro com a cidade: um esgoto pôde se transformar num bonito riacho, uma casa de máquinas fazia vezes de uma bela casa de campo e a praia foi retratada num formato que a aproximava da imagem de um sítio.

Delineava-se, assim, uma cartografia particular do bairro, construída a vários olhos e mãos, mas, em sua faceta de real, talvez impossível de se apreender completamente, afinal, "[...] jamais se deve confundir uma cidade com o discurso que a descreve" (Calvino, 1972, p. 2). A cidade cartografada, portanto, parecia ir além dos traçados geo- 
gráficos registrados em imagem. Nos relatos dos jovens sobre a busca por lugares e iluminações perfeitas para fotografar, eles pareciam caminhar sem destino certo; o caminhar era o próprio destino. Os trajetos cristalizados, naturalizados ganhavam, assim, novos contornos. A cidade percorrida era invisível aos olhos alheios, ainda que fosse um espaço pelo qual outras pessoas também circulavam diariamente. $\mathrm{O}$ que haveria de diferente? Sem dúvidas, a experiência. Experiência compartilhada entre pares e conosco, que dava testemunho das incursões dos jovens num espaço que, de tão familiar, subitamente, lhes parecia estranho, novo.

A inserção na cultura, no laço social e, portanto, na pólis não constitui uma tarefa simples; exige uma passagem delicada e, igualmente, criativa, que implica num intenso trabalho psíquico a ser empreendido pelo jovem. Em nossa pesquisa, tomamos esse ato de sair do espaço físico da escola e adentrar a cidade para fotografá-la - não como quem simplesmente passa, mas como alguém que passeia e recolhe fragmentos desse percurso, que poderão ganhar novos sentidos no après-coup - como uma metáfora da própria operação adolescente de deslocar-se do laço familiar em direção ao social (Rassial, 1999); deslocamento esse que pode vir a funcionar como um meio pelo qual o jovem consiga construir e se apropriar de um lugar para si, não necessariamente no mercado de trabalho, elegendo novos referenciais que o sustentem na vida, numa tentativa de criar vias de afirmação criadora para o sujeito em seu processo de transição para a vida adulta.

\section{À Guisa de Conclusão}

Assistimos, hoje, à estruturação de uma nova discursividade nas searas educativas. A aliança entre educação e trabalho vem-se configurando como uma verdadeira submissão das práticas educativas, em especial, aquelas voltadas ao público jovem, às demandas provenientes do setor econômico, de modo que as produções simbólicas da cultura, incluindo, aí, a própria ciência, passam a ser convertidas em mercadoria num processo que põe em pleno funcionamento as engrenagens do sistema capitalista.

Nesse contexto, a escola perde a sua significação enquanto templo do saber, distanciando-se, cada vez mais, de uma perspectiva formativa e conduzindo seus alunos em direção a uma semiformação vaga e superficial. Atuando, agora, como uma organização prestadora de serviços, passa a oferecer, como produto, a formação profissional que os modelará para o mercado da maneira mais eficiente possível. Assim, o tecnicismo passa a assumir um papel estratégico no delineamento de práticas educativas tidas como mais modernas e inovadoras, já que as metodologias adotadas seguem na direção de treinar os jovens para a aplicação adequada dos conhecimentos técnicos adquiridos.

Diante desse cenário, o tecnicismo vem imprimindo mudanças irreversíveis na relação do sujeito com o campo do saber. Os alunos, não mais educados numa perspectiva libertadora e emancipatória, tornam- 
A Juventude En-Cena na Escola

se alvos fáceis das alienantes estratégias de marketing publicitário que presenciamos na atualidade. Com o avanço das tecnologias da informação e da comunicação, que encontram sua culminância, do ponto de vista mercadológico, nas redes sociais e aplicativos de compras virtuais - os novos shopping centers da atualidade -, assistimos a uma nova modalidade de relação dos jovens com a imagem tomar forma.

Hoje, somos bombardeados por uma tal quantidade de imagens a ponto de não podermos distinguir mais a experiência direta daquilo que vimos há poucos segundos na televisão. Em nossa memória se depositam, por traços sucessivos, mil estilhaços de imagens, semelhantes a um depósito de lixo, onde é cada vez menos provável que uma delas adquira relevo (Calvino, 1990, p. 107).

Esses estilhaços de imagens pré-fabricadas e amplamente difundidas pela cultura contemporânea, ao excluírem dimensão do ato criativo pela reprodutibilidade técnica que lhes dá origem, estariam produzindo, como efeito, a perda da capacidade humana de imaginar, de contar histórias dignas de serem narradas (Miranda, 2007). Não haveria, portanto, uma mediação entre o sujeito e as imagens que visualizamos pelas telas de dispositivos eletrônicos que carregamos nos bolsos como extensão do próprio corpo.

Assim, o próprio processo por meio do qual o jovem pode inserirse no plano da cultura a partir da transmissão dos referenciais simbólicos da sociedade, fica prejudicado. $\mathrm{O}$ uso da imagem fotográfica como criação, e não como reprodução técnica, e a construção de narrativas que levavam em conta a dimensão da alteridade - visto que o sentido da imagem só pode-se construir "[...] mediado pelo diálogo com os outros sujeitos que, igualmente, experimentam a avalanche de estímulos que nos circundam cotidianamente" (Miranda, 2007, p. 36) -, funcionaram como via de afirmação criadora para o enlace do sujeito ao espaço da cidade.

Com base nos achados da nossa pesquisa, consideramos que o combate à sujeição da educação à lógica de mercado deve estar atravessado por estratégias que conduzam à singularização da experiência educativa para que, a partir daí, algum efeito subjetivo se faça produzir. Assim, concluímos que, se a escola não se implica numa proposta educacional que faça frente à sua organização em função do capital, acaba por ficar impossibilitada de cumprir seu papel enquanto espaço de formação, dificultando que os alunos construam algum sentido discernível à experiência de encontro com o saber. Aí, residiria a urgência de um posicionamento crítico constante. Há que se fazer furos num modelo educativo voltado à apropriação de instrumental técnico e receituário para a eficiência, afinal a escola deve fazer mais que formar para o trabalho, deve (re)assumir seu posto enquanto espaço potencial de emancipação e formar para a vida, para a pólis.

Recebido em 12 de novembro de 2020 Aprovado em 23 de fevereiro de 2021 


\section{Notas}

1 Esclarecimento, emancipação e autonomia são conceitos que se aglutinam na concepção de educação defendida por Adorno. Por esclarecimento devemos entender o processo por meio do qual o homem, pela luz da razão, liberta-se da tutela alheia, de modo a agir com autonomia e sem a orientação de outrem (Kant, 1985 [1784]). Essa autonomia, por sua vez, não consistiria na ausência de condicionamentos externos, mas na capacidade de embasar-se em princípios morais - somente possíveis num contexto cultural - para se tomar as próprias decisões e responsabilizar-se por elas (Zambillo, 2015). Por último, a emancipação, seguindo a tradição iluminista, consistiria no ato de o homem, pela via do saber, tornar-se agente de transformação da sua própria história, rompendo com as determinações sociais que o alienam a uma lógica pela qual, não raro, ele nem mesmo se percebia regido.

2 Inclusão nossa.

30 termo futuro presente no título da oficina faz referência à temporalidade enunciada no texto, mas também ao bairro no qual se situa a escola: Praia do Futuro, por isso a opção pela grafia em letra maiúscula.

$4 \mathrm{O}$ nome atribuído ao perfil criado para a oficina foi escolhido pelos próprios jovens: @restosdeumfuturo.

5 Optamos por não identificar os alunos, ainda que com nomes fictícios, por partirmos da compreensão de que as falas aqui evocadas tratam de narrativas construídas por e entre vários. Assim, foram tomadas como efeito da própria circulação da palavra que, ao ser proferida, retornava diferente, reverberando, em cada um, algo que dizia respeito ao coletivo.

6 O feed é o espaço do instagram que reúne todas as publicações permanentes do usuário e serve como um resumo do conteúdo que já foi produzido por ele. Devido à rede social estar, cada vez mais, se configurando como um espaço de divulgação profissional, costuma ser utilizado como um meio de projetar o conceito e o visual que se pretende transmitir aos seguidores do perfil.

\section{Referências}

AICHHORN, August. Juventud Desamparada. Barcelona: Gedisa, 2006. [1925]. ADORNO, Theodor. O que significa elaborar o passado. Tradução de Wolfgang Leo Maar. In: MAAR, Wolfgang Leo. Educação e emancipação. São Paulo: Paz e Terra, 2003. P. 139-154. [1959].

ADORNO, Theodor. Teoria da semiformação. Tradução de Newton Ramos de Oliveira, Bruno Pucci e Cláudia Barcelos de Moura Abreu. In: PUCCI, Bruno; ZUIN, Antônio; LASTÓRIA, Luiz. Calmon Nabuco (Org.). Teoria Crítica e Inconformismo: novas perspectivas de pesquisa. Campinas: Autores Associados, 2010. P. 07-40.

ADORNO, Theodor; BECKER, Hellmut. Educação e Emancipação. Tradução de Wolfgang Leo Maar. In: MAAR, Wolfgang Leo. Educação e Emancipação. São Paulo: Paz e Terra, 2003a. P. 169-185. [1969].

ADORNO, Theodor; BECKER, Hellmut. Educação - para quê? Tradução de Wolfgang Leo Maar. In: MAAR, Wolfgang Leo. Educação e Emancipação. São Paulo: Paz e Terra, 2003b. P. 139-154. [1967]. 
A Juventude En-Cena na Escola

BANDEIRA, Belkis Souza; OLIVEIRA, Avelino da Rosa. Formação Cultural e Semiformação: contribuições de Theodor Adorno para pensar a educação hoje. Educação, Porto Alegre, v. 35, n. 2, p. 225-232, maio/ago. 2012.

BAUMAN, Zygmunt. Modernidade Líquida. Rio de Janeiro: Jorge Zahar Editor, 2001.

BENJAMIN, Walter. Paris do segundo império. In: BENJAMIN, Walter. Obras Escolhidas III: Charles Baudelaire - um lírico no auge do capitalismo. São Paulo: Brasiliense, 1989. P. 01-65.

BENJAMIN, Walter. A Obra de Arte na Era de sua Reprodutibilidade Técnica. In: BENJAMIN, Walter. Obras Escolhidas I: magia, técnica, arte e política. São Paulo: Brasiliense, 1994. P. 165-196. [1935-1936].

BRASIL. Lei no 9.394, de 20 de dezembro de 1996. Estabelece as Diretrizes e Bases da Educação Nacional. Diário Oficial [da República Federativa do Brasil], Brasília, DF, v. 134, n. 248, 23 dez. 1996. Seção I. P. 27834-27841.

BRASIL. Ministério da Educação. Secretaria de Educação Média e Tecnológica. Referenciais Curriculares para a Educação Profissional Técnica. Brasília: MEC, 2000.

BRASIL. Resolução no 6, de 20 de setembro de 2012. Define as Diretrizes Curriculares Nacionais para a Educação Profissional Técnica de Nível Médio. Diário Oficial [da República Federativa do Brasil], Brasília: DF, 21 set. 2012. Seção I. P. 22.

BRASIL. Ministério da Educação. Secretaria de Educação Básica. Diretoria de Currículos e Educação Integral. Diretrizes Curriculares Nacionais da Educação Básica. Brasília: MEC, SEB, DICEI, 2013. P. 562.

BRASIL. Ministério da Educação. Instituto Nacional de Estudos e Pesquisas Educacionais Anísio Teixeira. Indicadores de fluxo escolar da educação básica. Brasília: INEP, 2017.

CALVINO, Ítalo. Cidades Invisíveis. São Paulo: Biblioteca Folha, 1972.

CALVINO, Ítalo. Seis Propostas para o Próximo Milênio. São Paulo: Companhia das Letras, 1990.

COSTA, Sylvio de Sousa Gadelha. Governamentalidade Neoliberal, Teoria do Capital Humano e Empreendedorismo. Educação \& Realidade, Porto Alegre, v. 34, n. 2, p. 171-186, maio/ago. 2009.

COUTINHO, Luciana Gageiro; POLI, Maria Cristina. Adolescência e o Ocupa Escola: retorno de uma questão? Educação \& Realidade, Porto Alegre, v. 44, n. 3, p. 1-19, 2019.

ELIA, Luciano. A Transferência na Pesquisa em Psicanálise: lugar ou excesso? Psicologia: reflexão e crítica, Porto Alegre, v. 12, n. 3, p. 00, 1999.

FREUD, Sigmund. Algumas Reflexões sobre a Psicologia do Escolar. In: FREUD, Sigmund. Edição Standard Brasileira das Obras Psicológicas Completas de Sigmund Freud (volume XIII). Rio de Janeiro: Imago, 2006a. P. 243-250. [1914].

FREUD, Sigmund. Recomendações aos Médicos que Exercem a Psicanálise. In: FREUD, Sigmund. Edição Standard Brasileira das Obras Psicológicas Completas de Sigmund Freud (volume XII). Rio de Janeiro: Imago, 2006b. P. 123-136. [1912].

GAGNEBIN, Jeanne-Marie. Lembrar Escrever Esquecer. São Paulo: Editora 34, 2006. 
HUBERMAN, Leo. A História da Riqueza do Homem. Rio de Janeiro: Zahar Editores, 1981. [1936].

KANT, Immanuel. Resposta à Pergunta: que é 'esclarecimento'? In: KANT, Immanuel. Textos Seletos. Tradução de Floriano de Sousa Fernandes. Petrópolis: Vozes, 1985. P. 100-117. [1784].

LACAN, Jacques. O Seminário, Livro 11: os quatro conceitos fundamentais da psicanálise. Rio de Janeiro: Jorge Zahar Editor, 1988. [1964].

LACAN, Jacques. O Seminário, Livro 17: o avesso da psicanálise. Rio de Janeiro: Jorge Zahar Editor, 1992. [1969-1970].

LACAN, Jacques. A Ciência e a Verdade. In: LACAN, Jacques. Escritos. Rio de Janeiro: Jorge Zahar Editor, 1998. P. 869-892. [1965-1966].

LAVAL, Christian. A Escola Não É uma Empresa: o neoliberalismo em ataque ao ensino público. São Paulo: Boitempo, 2019.

LIMA, Maira Sampaio Alencar; LIMA, Maria Celina Peixoto Lima. Dos Discursos Freudianos sobre a Educação: considerações acerca da inibição intelectual. Psico, Porto Alegre, v. 42, n. 2, p. 212-219, abr./jun. 2011.

MAAR, Wolfgang Leo. À Guisa de Introdução: Adorno e a experiência formativa. In: MAAR, Wolfgang Leo. Educação e emancipação. São Paulo: Paz e Terra, 2003. P. 10-27.

MIRANDA, Luciana Lobo. A Cultura da Imagem e uma Nova Produção Subjetiva. Psicologia Clínica, Rio de Janeiro, v. 19, n. 1, p. 25-39, 2007.

PEREIRA, Marcelo Ricardo. Os Profissionais do Impossível. Educação \& Realidade, Porto Alegre, v. 38, n. 2, p. 485-499, abr./jun. 2013

RASSIAL, Jean-Jacques. O Adolescente e o Psicanalista. Rio de Janeiro: Companhia de Freud, 1999.

RIBEIRO, Paulo Rennes Marçal. História da Educação Escolar no Brasil: notas para uma reflexão. Paidéia, Ribeirão Preto, v. 4, p. 15-30, fev./jul. 1993.

ROUANET, Paulo Sérgio. Édipo e o Anjo: itinerários freudianos em Walter Benjamin. Rio de Janeiro: Tempo Brasileiro, 2008.

SAVIANI, Dermeval. O Trabalho como Princípio Educativo Frente às Novas Tecnologias. In: FERRETTI, Celso et al. (Org.). Novas Tecnologias, Trabalho e Educação. Petrópolis: Vozes, 1994.

SAVIANI, Dermeval. O Choque Teórico da Politecnia. Trabalho, Educação e Saúde, Rio de Janeiro, v. 1, n. 1, p. 131-152, mar. 2003.

SCHULTZ, Theodore. Capital Humano: investimentos em educação e pesquisa. Rio de Janeiro: Zahar Editores, 1973.

VOLTOLINI, Rinaldo. O Conhecimento e o Discurso do Capitalista: a despsicologização do cotidiano social. Estilos da Clínica, São Paulo, v. 17, n. 1, p. 106-121, 2012.

WINNICOTT, Donald. O Brincar e a Realidade. Rio de Janeiro: Imago, 1975. [1971]

ZAMBILLO, Marciana. Autonomias Errantes: entre modos de ser autoimpostos e possibilidades de invenção de si. 2015. 154 f. Dissertação (Mestrado) - Programa de Pós-Graduação em Psicologia Social e Institucional, Universidade Federal do Rio Grande do Sul, Porto Alegre, 2015. 
Lorenna Pinheiro Rocha é professora do curso de Psicologia da Universidade de Fortaleza. Mestra em Psicologia Social e Institucional pela Universidade Federal do Rio Grande do Sul. Doutoranda no Programa de Pós-Graduação em Psicologia da Universidade de Fortaleza.

ORCID: http://orcid.org/0000-0002-4594-3235

E-mail: lorennapinheiro@hotmail.com

Maria Celina Peixoto Lima é professora titular do Programa de Pós-Graduação em Psicologia da Universidade de Fortaleza, Doutora em Psicologia pela Universidade Paris 13 (França), Membro do GT da ANPEPP "Psicanálise e Educação".

ORCID: http://orcid.org/0000-0002-9305-079X

E-mail: celina.lima@unifor.br

Editora-responsável: Fabiana de Amorim Marcello

Este é um artigo de acesso aberto distribuído sob os termos de uma Licença Creative Commons Atribuição 4.0 Internacional. Disponível em: <http:// creativecommons.org/licenses/by/4.0>. 